\title{
Integrated disclosure - Streamlining the disclosure norms in the Indian securities market
}

\author{
Sandeep Parekh \\ Visiting Faculty \\ sandeep.parekh@phparekh.com
}

\begin{abstract}
An increasing focus on improved disclosures has been the regulatory thrust of securities regulations since the great crash of 1929. India gave up the merit based system of a controller regulating the issue of securities in favour of the disclosure based regulatory philosophy in 1988. Since then an increasing focus on public disclosure has been a priority with SEBI, the Indian regulator.
\end{abstract}

However, in an attempt to improve the quality of disclosure, a necessary waste product has developed - that of the quantity of disclosure. Today with new regulations being added by the legislature, SEBI and stock exchanges, we see an excessive duplication of disclosure particularly of listed companies.

There are several areas where net disclosure of information can be maintained even while reducing the quantity of information brought out. This paper examines some areas which require reduction of information flow because the information is already out in the public domain. The paper advocates a transition to a company registration with greater emphasis on continuous disclosures and a relatively easy track for seasoned companies to raise capital without an extensive prospectus centered regulations. 


\section{INTRODUCTION}

\section{Disclosure}

When a company attempts to access the 'public' for raising capital, it must go through a complex and long process. Much of the process relates to collecting, collating and presenting information about the company to prospective shareholders of the company. This philosophy of disclosure is premised on the simple idea that securities represent a bundle of rights which are not visible to an offeree of securities and such offeree must know the underlying company and the nature of the bundle of rights before such investor invests. Disclosure also reduces the possibility of wrongdoing. Even if a disclosure is not read by anyone, the fact that something needs to be disclosed will provide a good prophylactic against wrongdoing. The idiom that 'sunlight is the best disinfectant' succinctly describes a whole philosophy in the securities market.

While disclosure is a good thing, the good thing costs a good deal of money. A typical primary market issue could cost over $10 \%$ of the capital raised (though much of it also relates to costs incidental to disclosure costs). This cost is borne by the shareholders of the company and therefore disclosures must be looked as generally good but also as an expensive general good. Further, to the extent that management is diverted from their usual function in gathering information for an issue, there is a direct economic opportunity cost.

\section{Issuer information and offering information}

A public company which has previously tapped the capital market must comply with disclosure norms under the Companies Act, SEBI regulations and under the listing requirements of stock exchanges. To the extent company related information of such companies is already out in the public domain, part of the disclosure made in tapping the capital markets is repetitive and adds no value. Here it is important to distinguish between company information and transaction based information. The former is already out in the public domain, while the latter which relates to the particular issue of capital needs to be published. Such transactional details would include details of types of securities offered, underwriting commissions paid, intended proceeds of capital raised etc. By contrast 
company detail would include the issuer's business, management compensation, capital structure and recent financial results.

\section{Efficient Capital Market Hypothesis}

The theory of integrated disclosure is premised on the efficient capital market hypothesis ("ECMH"). According to the $\mathrm{ECMH}$, information put out in the public domain is promptly impounded in the price of a security. Thus once information is already out in the public domain, no value addition will arise out of repeating the same information when capital is raised.

\section{Background - US}

A 1966 article by Milton Cohen in the Harvard Law Review "Truth in Securities revisited" was a seminal piece on the need for non duplicative disclosures. Mr. Cohen advocated that continuous disclosure should be strengthened and issue of capital should invite minimal and only transaction based information. Any correction, updates or supplementation to the continuing disclosure can also be provided to prevent staleness of company information. The article led to an SEC led study called the Wheat Report which sought to research implementation of the principles of integrated disclosure. It later translated into the adoption of a single standard of information for both primary issues and continuous disclosure for seasoned issuers. A seasoned issuer could thus incorporate by reference company information which was already out in the public domain. Where a company was coming to the primary market for the first time, the standards remained as in the past. Also introduced was the concept of shelf registration. Shelf registration allows multiple issues of securities with a single prospectus with a requirement to update the prospectus periodically and to distribute transaction details with each issue.

In $1966 \mathrm{Mr}$. Cohen predicted "At some point in the foreseeable future it will surely be economically feasible, as it is probably now technically feasible, to record all filed information in a computer for instant retrieval and communication - to produce a prospectus on call, so to speak." With today's technology, we are still far from that vision though technologically such a vision is within easy reach. 


\section{Implementation of integrated disclosure in India - shelf registration}

We already have a sampler of integrated disclosure in the form of shelf registration in India, the basic terms of which are contained in S. 60A of the Companies Act. However, the limited scope of the section makes it available only to a very select industry and that too for specific types of securities.

There is a need to broaden the scope of shelf registration to all seasoned issuer and also bring equity within the scope of permitted securities. However, the market itself may have some concerns about shelf registration. In particular, underwriters are uncomfortable with shelf registration because of the difficulty of doing a thorough due diligence for the period of currency of the prospectus. While there is a need to enlarge the scope of companies and securities which should be allowed under the shelf route, a more powerful change in the disclosure norms would be the best way forward. And that can be achieved by moving from issue registration to company registration.

\section{Moving beyond shelf registration to company registration}

The goal of reduction of duplication and a holistic approach to disclosure can come about only when we are able to move from registration of issue of securities to a model where the company itself is registered. Under the proposed structure, there will be a need to strengthen the existing disclosure norms so that information which is sought for only at the time of issue becomes generally available not only to offerees of new securities but to existing shareholders as well. As a result, full disclosure would be enjoyed by a larger class of investors and proposed investors; at the same time by avoiding duplication, issue costs would come down and seasoned companies with a reliable track record would be able to raise capital easily and at a lower net cost of capital.

\section{The continuous report}

As an integrated scheme comes to play, today's rather fragmented piecing of information in dozens of filings with several regulatory bodies would be replaced by a document which would piece together the various regulatory documents by using hyperlinks. The document would be like a hyperlinked annual report, with links to all public filings made to any regulatory authority and thus in the public domain, except it 
would not be an annual report but a continuing report. The proposed master report of the company would be updated more frequently and would be in plain English and readable by any person. At the same time complex and technical issues and other filings in their full glory would be available with a hyperlink.

Anyone who has paid a visit to a Registrar of Companies office would know how theoretical public dissemination of information can be. Given today's technologies relying on the antiquated and grossly inefficient form of filings which vanish into a theoretical public domain is unforgivable. The information could be in the form of a file put up on the website of the company/Sebi's edifar and copies of the same could be circulated on CDs. The proposed scheme could transform today's theoretical disclosures to a real distribution of information. To people who would argue that this would be unfair given that the penetration of PCs and the internet in India is too low, a paper document without the linked information could be sent on request.

It would be inappropriate to argue for a company registration scheme to replace the existing scheme of disclosure without understanding the pitfalls of such a scheme. The proposed model can only be introduced if the problems which would arise from this alien model are understood and met.

\section{The argument for duplication}

Much of the duplication in corporate disclosure can be attributed to the slow accretion to the body of regulations. Thus new regulations add to the old, sacrificing an efficient quantum of disclosure at the alter of not missing any detail. Duplication can also arise because the corporate law requirements are inadequate and SEBI while able to implement a holistic framework is unable to delete statutory provisions like those contained in the Companies Act.

There are cogent reasons for allowing duplication of disclosure. Unless one is able to overcome the arguments for duplication, it is difficult to justify the introduction of an integrated form of registration. 
First, if information is not truly in the public domain, then a last mile delivery of company and transaction detail i.e. prospectus will become important. Disclosure after all is different from a theoretical filing with the registrar. The registrar of company offices are known in India for making public information nearly impossible to access. Thus to that extent information has not entered public domain and needs to be disclosed.

Second, if the two disclosures are qualitatively different, then a superior primary market disclosure would be important even though parts of the disclosure would already have been made. The quality of primary market disclosure is also superior because it passes through various due diligences, particularly by the investment bank.

Third, if there are different liabilities attached to primary market versus continuing disclosure, then management would be more careful of disclosing information to prospective shareholders than to the current shareholders who could be more tolerant of mistakes. This is pronounced in the detailed liabilities attached to issuer, management, directors, signatories and experts under the Indian Companies Act (see sections 62 and 63) for prospectus based violations. The liability for wrong disclosure in the annual report is by contrast more generic.

Fourth, listed companies are mandated to file audited annual financial accounts in the annual reports to shareholders. They also file quarterly numbers and make them public. However, if such information is used for issue of shares there is a possibility that the information has become stale by upto 3 months.

Fifth, a continuing disclosure of a listed company may be less coherent or readable because of the dozens of filings made over the past to the stock exchange, registrar, SEBI or other bodies. It would not be fair to expect the investor to sweep the public domain for bits and pieces of information and piece them together to get the real picture. By contrast, primary issue prospectus is information contained in a single document and thus readable.

Sixth, SEBI gives a more thorough look to a primary market prospectus than it does to annual filings. 


\section{Arguments supporting integrated disclosure}

Each of the arguments against an integrated approach and for continuing the status quo must be tested. If the arguments can be met by some modifications to our current thinking, it may be appropriate to modify some of the requirements.

\section{Public domain}

While public bodies may not be forthcoming in making filings truly public, there is nothing which stops companies from putting up the same information which they filed with public bodies and which is of public nature on their web site. In fact this would be one of the basic premises of a streamlined means of disclosure. For a company to use integrated disclosure, they must by necessity fulfill certain conditions; the first of which is to make all theoretically public information truly public by putting them up on their websites. But for such compliance, the company would be ineligible from using the integrated form of registration.

\section{Superior prospectus disclosure}

It is certainly true that the information contained in a prospectus is qualitatively superior to that filed in annual and quarterly reports of the company. However, that is not an argument in itself for discarding integrated disclosure. That is instead, a reason why continuing disclosure should be strengthened. Such improvement will not only bolster the prospective shareholders but also the existing shareholders who till now have been getting inferior information.

\section{Liability issues}

Specific and more burdensome liabilities attach to primary issue violations as contrasted with more generic penalties for misstatements in the annual report and quarterly figures. Thus, if continuing disclosures attract an easier burden of proof, one could argue that wrongdoers would have an easier time under the proposed mechanism. This issue too can be rectified. Top management could be required to file an attestation that they are not aware of any misleading disclosure and have not omitted any relevant material information. The liability of various intermediaries would apply as they would to a 
prospectus. The underwriter would need to conduct a major due diligence at a regular interval, say once in two years.

Any correction or update to the continuing duties of reporting would be made before an issue is made of securities. This would accompany the transaction based details which would be distributed before each issue. These transaction details would include as assessment of risk factors by the management. And each of these would attract liabilities similar to those seen in today's primary issue regulations.

\section{Problem of staleness}

The problem of staleness can easily be rectified as discussed above. With each issue the management and directors would need to circulate two important categories of information. First any corrections and updates to the information related to the company and second full blown transaction detail. Since a higher duty would be placed on updating the continuing disclosures even absent an issue, the duty to update and correct would presumably be minimal.

\section{Coherence and readability}

With filings being made to multiple regulatory authorities, the ability to patch different pieces of information to create a collage is a daunting task even for an analyst who is spending considerable time to collate the information. The answer to the problem really lies with the company which needs to make sense out of the mass of information. The company information can easily be put into a single document known as the continuously updated report (similar in structure to the annual report) with hyperlinks to various public filings made by it to various authorities. With today's technology such hyperlinks can provide a very readable document which does not compromise on depth of information which would be only one or two clicks away. Thus the basic document would be in readable simple English with links to more detailed, complex and subtle information. A company wishing to make use of the integrated disclosure should be mandated to have such a readable document which does not at the same time compromise on detail or complexity. In India we anyway have an abbreviated prospectus in small type font and 
attached to the application form which is a great and unique system which ought to continue.

\section{SEBI scrutiny}

This is perhaps the most difficult issue to overcome. While prospectuses are combed by the regulator for disclosure violations, its control over a company would be diluted in the proposed environment. With India's list of 9000 listed companies, many of which do not even comply with listing norms, it would be giving invitation to scandal to implement the scheme for all companies which are listed and thus presumably giving out information to the public domain. Taking the Indian reality, implementing the scheme would need to be done very cautiously and selectively. A company based registration should be allowed only for seasoned, well tracked company which have a record of complying with disclosure norms for at least five years. A pilot project could be begun by allowing companies on which derivatives are traded (over 60 companies, which are quite well tracked on a continuing basis) to use the scheme of company registration. Slowly, the list could be expanded once more companies are found to be followed by analysts and thus the information they bring out is consistently being impounded in the price.

\section{The transition}

Any transition to a company based registration must be selective and should be tested in phases. The first phase could be broadening the scope of shelf registration to a larger number of companies and also available to raising of equity besides debt. A second stage would be to introduce a system similar to the present US system where standardized company information is used for both continuing disclosure and for the company related information in a prospectus. Thus a prospectus would have two parts one relating to the company which will look either identical to the continuing disclosure or the information could be incorporated by reference; the second part relating to transaction based information.

The final phase would result in a transition to a company registration where seasoned companies would have the option of keeping its annual information continuously 
updated and put on a website and in turn would have the privilege of going public on a brief transactional memorandum with minimal time delay and regulatory barriers.

\section{Conclusion}

Relying on a regulatory framework based on the requirements of a different era may be a costly error which we might already be making. It would be useful to rewrite the rules and start thinking without any previous conditioning. We can improve disclosure by strengthening continuous disclosures and reducing duplication for which there is substantial cost and no benefit. If we could do that with today's technology and thus improve the quality of information while reducing the quantity, information would become more readable, access to people will be wider and an empty formality of registration could be translated into true 'on tap' disclosure available to all continuously. Data concerning business, property, management, financial condition, and results would be available at all times and updated in a single document whether there is an issue of capital or not. On the other hand a much lighter version of memorandum of transactional details could be made with each issue. Thus making raising of capital cheaper and easier, information more accurate and more widely available - benefiting both issuer and investor. The intermediaries like investment bankers would have a leaner role in capital raising but a much more substantial role on a continuous basis.

Any comments can be addressed to

Sandeep Parekh

P.H. Parekh \& Co.

sandeep.parekh@phparekh.com or spparekh@,iimahd.ernet.in

or by telephone at (91) (11) 51526601 


\section{REFERENCES}

Truth in Securities revisited, Milton Cohen, Harvard Law Review, May 1966

Reforming US Disclosure Rules in Global securities markets, Kun Young Chang, Annual Review of Banking and Financial Law, 2003.

Shelf registration, integrated disclosure, and underwriter due diligence: an economic analysis, Merritt B. Fox, Virginia Law Review, June 1984

Blinded by the light: Information Overload and its consequences for securities regulations, Troy A Paredes, Washington University Law Quarterly, Summer 2003

Death in One Act: The case for company registration, Michael Mcdonough, Pepperdine Law Review, January 1997.

SEC Release, Adoption of Integrated Disclosure system, 3 March 1982

SEC Release No. 33-6383, Adoption of Integrated Disclosure system, 16 March 1982

SEC Release, Shelf registration, 17 Nov 1983

SEC Release No. 33-6499, Shelf Registration, 23 Nov 1983

SEC Release, Summary Prospectuses, 22 June 1990

SEC Release No. 33-8501, Securities offering reform, 3 Nov 2004 